\title{
Health inequalities and development plans in Iran; an analysis of the past three decades (1984-2010)
}

Hossein Zare ${ }^{1,2,3^{*}}$, Antonio J Trujillo², Julia Driessen ${ }^{4}$, Mojtaba Ghasemi ${ }^{5}$ and Gisselle Gallego ${ }^{6,7}$

\begin{abstract}
Introduction: Reducing inequalities in health care is one of the main challenges in all countries. In Iran as in other oil-exporting upper middle income countries, we expected to witness fewer inequalities especially in the health sector with the increase in governmental revenues.

Methods: This study presents an inequalities assessment of health care expenditures in Iran. We used data from the Household Income and Expenditure Survey (HIES) in Iran from 1984-2010. The analysis included 308,735 urban and 342,532 rural households.

Results: The results suggest heightened inequality in health care expenditures in Iran over the past three decades, including an increase in the gap between urban and rural areas. Furthermore, inflation has affected the poor more than the rich. The Kakwani progressivity index in all years is positive, averaging 0.436 in rural and 0.470 in urban areas during the time period of analysis. Compared to inequality in income distribution over the last 30 years, health expenditures continuously show more inequality and progressivity over the same period of time.

Conclusions: According to the result of our study, during this period Iran introduced four National Development Plans (NDPs); however, the NDPs failed to provide sustainable strategies for reducing inequalities in health care expenditures. Policies that protect vulnerable groups should be prioritized.
\end{abstract}

Keywords: Inequality, Health services, Health inequalities, Gini, Development plans, Kakwani, Gender inequalities, Out-of-pocket

\section{Introduction}

Health care is a fundamental human right and one of the first responsibilities of a government is to establish effective and sustainable interventions to address inequality in health care [1] and protect low-income, vulnerable groups such as women and children, the elderly and the chronically ill [2]. In this regard, health care policymakers have long been concerned with protecting people from ill health that could lead to catastrophic household payments [3], which often push households into poverty [4].

Studies show that lower-income households have higher rates of catastrophic expenditures than higher-income groups $[5,6]$. These expenditures are shown to be one of

\footnotetext{
* Correspondence: hzare1@jhu.edu

${ }^{1}$ Health Policy and Management Department, Johns Hopkins Bloomberg School of Public Health, 624 North Broadway, Baltimore, Maryland 21205, USA

2Department of International Health, Johns Hopkins Bloomberg School of Public Health, 615 North Wolfe Street, Baltimore, Maryland 21205, USA Full list of author information is available at the end of the article
}

the major factors compromising equitable health care systems in low-income countries [3,7]. The increase in health care expenditures coupled with high inflation rates-especially in developing countries-has increased out-of-pocket spending for health care, forced people to reject or quit treatment, and impacted household living standards [7]. The most devastating consequences of catastrophic payments are realized by those who are already poor, and who have to limit their expenditures to basic necessities such as food, and housing in order to afford health care [8]. Although there is no universal strategy for reducing catastrophic payments, universal health insurance [9], social protection systems [1], and exclusion of vulnerable groups from high cost-sharing payments are common strategies for protecting vulnerable populations [2] from the consequences of catastrophic payments [10].

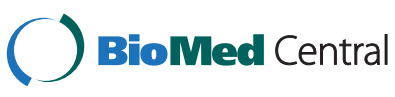

(c) 2014 Zare et al.; licensee BioMed Central Ltd. This is an Open Access article distributed under the terms of the Creative Commons Attribution License (http://creativecommons.org/licenses/by/2.0), which permits unrestricted use, distribution, and reproduction in any medium, provided the original work is properly credited. The Creative Commons Public Domain Dedication waiver (http://creativecommons.org/publicdomain/zero/1.0/) applies to the data made available in this article, unless otherwise stated. 
Iran is a resource-rich country whose economy is highly dependent on crude oil and, like other oil-exporting countries, relies on these export revenues for economic growth [11]; more than $70 \%$ of annual state finances and more than $80 \%$ of annual foreign-exchange earnings are from the export of crude oil [12]. Countries like Iran are said to be "cursed" by natural resources because the resource bonanza does not translate into economic growth or development of wealth due to the country's inability to successfully convert its depleting exhaustible resources into productive capital such as roads, buildings or health care systems [13]. The challenge for Iran and similar oilproducing countries is how to promote economic growth and develop wealth while reducing inequality among its citizens. As a country grows wealthier, it has more resources to spend on health care; however, studies and national health accounts have shown that resources allocated to the health care sector in Iran have been inadequate [14-17]. In recent years, Iran was expected to improve financial fairness and reduce economic barriers to accessing timely care for households facing catastrophic health events [16]. To this end, Iran rolled out its first five year economic, social, and cultural development plan (NDP) in 1989 [18]. Subsequent plans outlined the government's intention to further invest in infrastructure and manage the macro-economy [19].

The first NDP (1990-1994) focused on development of primary health care (PHC) networks and medical facilities, especially in rural areas, and improving policies around human resources, family planning, and population control [18]. Developing a universal health insurance scheme was the main objective of the second NDP (1994-1999). The government established the Medical Services Insurance Organization (MSIO) in 1995 under the provisions of the Universal Health Insurance Act to provide medical insurance for civil servants, the needy, villagers and other social strata [20].

The third NDP (2000-2004) focused more on developing health in Iran under a "welfare state" approach [21], including improving both quality and quantity of coverage in rural areas, developing inpatient coverage for urban low-income uninsured people and reducing the cost of drugs for those with chronic renal failure, hemophila and thalassemia [22].

The Ministry of Welfare and Social Security (MWSS) was established in the last year of the third NDP. The stated primary objective of the fourth NDP (2005-2009) was decreasing inequalities in health expenditures.

All of Iran's NDPs targeted economic inequality by prioritizing rural and lower-income groups, [18,21,23,24] and the then-leader (Ayatollah Khomeini) promised largescale redistributions of wealth and income [19]. A 2009 comprehensive picture of poverty and income inequality in Iran provided by Salehi-Isfahani concluded that, in spite of declining poverty and inequality immediately following the revolution in Iran, income inequalities had increased in recent years [19]. Despite the NDP's focus on improving health care access and equality, to date there are no studies evaluating the trend in health care expenditure inequality during the period of Iran's four NDPs. The main contribution of this paper is to describe the trends in health care expenditure inequality in Iran during the last three decades (1984-2010).

\section{Iran's health system}

The total population of Iran was approximately 50 million in 1986, and increased to 75 million by 2011 [25]. During this time, the percentage of the population residing in rural areas fell from 45.7 percent to 28.5 percent [25]. In 2008 total expenditures on health care comprised $7.8 \%$ of Gross Domestic Product (GDP) [17].

The Ministry of Health and Medical Education (MOHME) acts as the main steward of the health care system. Nearly all of the primary and more than $71 \%$ of secondary and tertiary hospitals and rehabilitation facilities are public; the remaining $29 \%$ are private or nongovernmental organizations (NGOs) [26]. The proportion of NGO facilities is less than two percent [26]. Financing of health care in Iran is a combination of public funds (governmental budget), social health insurance, private insurance premiums and out-of-pocket payments.

Iranian insurers receive insurance premium revenue from their members as well as government support from general tax revenue and the sale of natural resources (mainly oil) [27]. Although more than $90 \%$ of people are covered by some type of public insurance, social health insurance or private insurance, the National Health Account showed that around $56.8 \%$ of total health care expenditures are financed out-of-pocket [14,28]. Figure 1 shows the breakdown in health care expenditures by payer from 1984-2008. During this time the proportion of expenditures that were out-of-pocket ranged from $55.2 \%$ to $58.9 \%$. Household expenditure (Out-of-pocket payments) include household premium payments as well as direct payments for services. The lowest proportion of out-of-pocket spending was observed during the period of the second NDP. On average the government paid less than 25\% (24.6\%) from 1984-2008, with their largest contribution occurring during the second NDP. The Social Security Organization (SSO) was responsible for as much as $10 \%$ of health expenditures during this time. The MSIO as the main government health insurance organization represented on average $5.6 \%$ of health expenditures, peaking during the second NDP at $8.8 \%$. The "Other" group in Figure 1 includes private health insurance companies introduced as part of the health insurance market, which has more recently increased its payer presence in the health care system. 


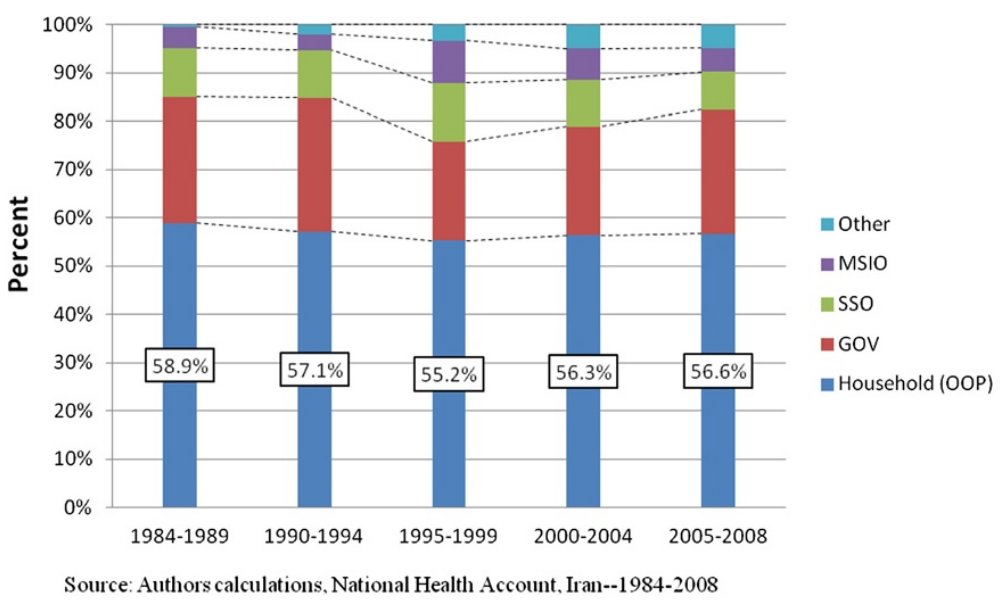

Figure 1 Comparing health care financing in four NDPs Iran.

\section{Methods}

\section{Data sources}

Data used for this study came from Iran's Households Income and Expenditure Survey (HIES) from 1984 to 2010. The HIES is a nationally and regionally representative household survey conducted annually by the Statistical Center of Iran (SCI). It collects basic demographic and economic characteristics of households. Data on expenditures, wages, and income are self-reported. We drew on micro-data sets of HIES for the years 1984 to 2010 [17]. Households are chosen for inclusion in the survey using a three-staged cluster sampling method with strata, with the goal of understanding the composition and distribution of income, expenditures, and consumption in both urban and rural households [28,29].

To ensure the quality of the data the SCI follows several steps [30]; Interviews are used to collect expenditure data with the respondents completing the interview by a mix of recall and using documentation, non-contacted households are substituted, but not refusal households and nonresponse is reduced using more than one repeat visits. Missing values are imputed for some occasions; supplementary sources are not used to adjust estimates for under- or overreporting; ethnic groups are excluded from data analysis.

These data have been used widely in other studies of health and household expenditures in Iran [19,27,31,32].

This study as a non-experimental research tried to compare income inequality and health inequality in Iran between 1984-2010. We used the pooled data from 1984-2010 includes 342,532 rural and 308,735 urban households; demographic characteristics of sample households are presented in Table 1.

\section{Analysis}

\section{Adjustment for the composition of households}

To account for the size and composition of each household, we converted household expenditures to per capita expenditures. We used a normalized household equivalence scale, including all households with heads at least 17 years of age and giving equal weight to all individuals in the household [33]. Total household expenditure is used as a proxy for household income, an approach recommended by Deaton as more reliable than self-reported income in surveys [34].

\section{Adjustment for health care and total expenditures}

Household expenditures are adjusted over time to account for inflation, which varies in urban and rural areas. Per capita health care expenditure distribution in urban and rural areas was adjusted using the Consumer Price Index (CPI), as published by the Central Bank of Iran (CBI) [35] for urban areas and Statistical Center of Iran (SCI) for rural areas [36].

\section{Inequality analysis}

\section{Gini coefficient}

The Gini Coefficient (GC) is the most common income inequality measure $[33,37,38]$, with many desirable properties such as mean and population size independence, symmetry and Pigou-Dalton transfer sensitivity [33]. The coefficient ranges from zero (representing perfect income equality) to one (representing perfect income inequality). It is a function of the Lorenz curve, which depicts the distribution of income in a sample. Perfect equality is given by a straight line from the origin to $(100,100)$, indicating that $\mathrm{x} \%$ of the population earns $\mathrm{x} \%$ of the cumulative income. In the case of complete inequality, in which the richest person earns all the income, the Lorenz curve would run along the $\mathrm{x}$-axis with a right angle at (100.0) to terminate at $(100,100)$. The greater the degree of inequality, the further the distance of the curve from the diagonal line running from the origin to the terminate point.

We focused on GC as a measure of inequality; it gave us the opportunity to compare inequalities in health 
Table 1 Comparing variables in urban and rural households - Iran: 1984-2010

\begin{tabular}{|c|c|c|c|c|c|c|}
\hline \multirow[b]{2}{*}{ Variable } & \multicolumn{2}{|r|}{ Urban } & \multicolumn{2}{|r|}{ Rural } & \multicolumn{2}{|r|}{ All } \\
\hline & No. & Percent & No. & Percent & No. & Percent \\
\hline Observation & 308,735 & $47.41 \%$ & 342,532 & $52.59 \%$ & 651,267 & $100.00 \%$ \\
\hline \multicolumn{7}{|l|}{ Gender (Household's Head) } \\
\hline Male & 280,571 & $90.88 \%$ & 303,895 & $88.72 \%$ & 584,466 & $89.74 \%$ \\
\hline Female & 28,165 & $9.12 \%$ & 38,636 & $11.28 \%$ & 66,801 & $10.26 \%$ \\
\hline \multicolumn{7}{|l|}{ Education (Head of Household) } \\
\hline No-education & 70,684 & $22.89 \%$ & 164,149 & $47.92 \%$ & 234,833 & $36.06 \%$ \\
\hline Basic education & 124,121 & $40.2 \%$ & 121,522 & $35.48 \%$ & 245,643 & $37.72 \%$ \\
\hline Diploma & 79,409 & $25.72 \%$ & 35,005 & $10.22 \%$ & 114,414 & $17.57 \%$ \\
\hline Some college & 34,521 & $11.18 \%$ & 21,856 & $6.38 \%$ & 56,377 & $8.66 \%$ \\
\hline \multicolumn{7}{|l|}{ Marital status (Household Head) } \\
\hline Married & 265,565 & $86.02 \%$ & 274,409 & $80.11 \%$ & 539,974 & $82.91 \%$ \\
\hline Widow & 23,544 & $7.63 \%$ & 40,513 & $11.83 \%$ & 64,057 & $9.84 \%$ \\
\hline Divorce & 2,080 & $0.67 \%$ & 2,260 & $0.66 \%$ & 4,340 & $0.67 \%$ \\
\hline Single & 5,367 & $1.74 \%$ & 12,217 & $3.57 \%$ & 17,584 & $2.70 \%$ \\
\hline Other & 12,179 & $3.94 \%$ & 13,133 & $3.83 \%$ & 25,312 & $3.89 \%$ \\
\hline \multicolumn{7}{|l|}{ Other household's characteristics } \\
\hline & No. & Mean (Std. Err.) & No. & Mean (Std. Err.) & No. & Mean (Std. Err.) \\
\hline Household size & 308,735 & $4.55(0.004)$ & 342,532 & $5.15(0.004)$ & 651,267 & $4.86(0.003)$ \\
\hline Age (Head of household) & 308,735 & $46.03(0.026)$ & 342,532 & $48.45(0.027)$ & 651,267 & $47.03(0.019)$ \\
\hline Real Per-Capita Annual Income (Total Household Exp.; Rials) & 308,735 & $40,384(84)$ & 342,532 & $18,823(36)$ & 651,267 & $29,044(46)$ \\
\hline Real Per-Capita Annual Total Health Exp. (Rials) & 308,735 & $2,283(26)$ & 342,532 & $1,217(11)$ & 651,267 & $1,719(14)$ \\
\hline
\end{tabular}

Source: Authors' calculations from Iran's Household Expenditure and Income Survey: 1984-2010.

Notes:

1. Household per capita annual income (Per capita annual Total Household Exp.) and per capita Total Household Exp. for health was adjusted by Consumer Price Index (CPI) and considering $1997=100$.

2. The gender distribution, literacy, marital status and income are significantly different between urban and rural areas. (P-values: 0.001$)$.

3. Different Obs. for Total Health Exp. related to some missing values.

expenditure with income inequalities (using total expenditure as proxy) over time and space. The cumulative frequency curve compares the distribution of total health care expenditures $y_{i}$ with the cumulative percentage of population $\mathrm{x}_{\mathrm{i}}$. The $\mathrm{GC}$ was calculated using the formula by Haughton (2009). Given a point $\left(\mathrm{x}_{\mathrm{i}}, \mathrm{y}_{\mathrm{i}}\right)$, the $\mathrm{GC}$ will be:

$$
G C=1-\sum_{i=1}^{N}\left(x_{i}-x_{i-1}\right)\left(y_{i}+y_{i-1}\right)
$$

where $N$ is the total number of observations. If $N$ is equal to the interval on the $\mathrm{x}$-axis, equation (2) can be simplified to:

$$
G C=1-\sum_{i=1}^{N}\left(y_{i}+y_{i-1}\right)
$$

\section{Progressivity analysis}

Widely used in public finance, the Kakwani progressivity index (KPI) has been used to measure the degree of progressivity in health care finance [39]. The Kakwani index is given by $K P I=C I-G C$ where $C I$ is the concentration index for out-of-pocket health expenditures:

$$
\begin{aligned}
& C I=1+1 / n+1 / n^{2} \mu\left(H E_{1}+H E 2+L+H E_{n}\right) \\
& n: \text { SampleSize; HE: HealthExpenditure, } \mu=\text { Mean }
\end{aligned}
$$

and GC is the Gini Coefficient for total household expenditure (income) [40]. The Kakwani index is equal to 1 in the most progressive system and -2 in the most regressive system [33].

\section{Results and discussion \\ Results}

In this study we used 27 years of data from the HIES, with 651,267 participating households in the total pooled sample. Table 1 compares mean absolute total expenditures and health care expenditures for urban and rural areas. Households in urban areas have higher levels of health expenditures than those in rural areas, 
but rural areas spend a larger proportion of their income on health.

According to the Iranian household structure around $90 \%$ of households in the sample are headed by males, around $23 \%$ of household heads have no formal schooling and approximately $90 \%$ of male household heads were married, compared to just $20 \%$ of female household heads.

Tables 2 and 3 report the inequality in the distribution of health care expenditures in urban and rural areas using the GC and KPI by year and NDP, respectively. It can be seen that inequality has persisted throughout the time period of analysis. From 1984 to 2010, inequality in health care expenditures (HE) was larger than the inequality for total expenditures; for example, mean GC in urban areas was 0.4448 for total expenditures and 0.7643 for total health expenditures.

While the analysis covers the time period 1984-2010, the first NDP was not adopted until 1989, and before that (1980-1988) Iran was engaged in the Iraq-Iran war. The GC on health expenditures peaks in urban areas towards the end of the war, and the urban KPI shows a lot of variation during this time as well. If we focus on the post-war period, health expenditure inequality remained high in both urban and rural areas until the mid-1990s, peaking in 1991 for rural and in 1992 for urban areas. Starting in the mid-1990s, inequality began to decline, a trend that continued until 2003 in both urban and rural areas.

Examining the trend in health expenditure inequalities across NDPs in Table 3, the lowest level of inequality is associated with the implementation of the third NDP. This does not necessarily indicate that the third NDP is solely responsible for improved inequality during this time, as the effect of the NDPs on inequality is likely somewhat lagged. This progress was not sustained in the fourth NDP, a time period that was associated with the most health inequality based on the GC in urban areas. The dynamics in rural areas were different, with the most post-war health inequality observed during the initial phase of the NDPs. This divergence in inequality trends in urban and rural areas may reflect the emphasis of the NDPs on addressing disparities in rural areas.

The KPI for health expenditure and total expenditure consistently indicated relative progressivity, with a greater degree of progressivity exhibited in health expenditures.

\section{Inequality in urban and rural areas}

Table 2 compares the inequality in health care expenditures between urban and rural households. There is less inequality in rural areas, both in terms of health care expenditures and total expenditures.

Dramatic fluctuations can be seen when studying the trend of changes in health care expenditure inequality in rural areas of Iran.
Table 2 and Figure 2(B) document the progressivity of health care expenditures, using the KPI between 1984 and 2010. The KPI is positive in all years for both urban and rural areas, with means of 0.436 and 0.467 in rural and urban areas, respectively. The KPI index declined in both rural and urban areas from 1993 until 2003, and then rose sharply in 2004, much like the GC.

As presented in Figure 2(C and D), in 1988, 1992, 2004, 2007, there is a sharp increase in the Gini index for total health expenditure in urban areas and in 1988, 1991, 2004, 2006 and 2009, in rural areas, with the highest level observed in 1991 (0.795 for rural) and 0.785 in 2007 for urban areas; in the mid-2000s, the level of inequality reverts to, and eventually exceeds, war-time levels. Despite the introduction of universal coverage in 1995 [20] and changes in infrastructure that included expansion of the national health insurance coverage and implementation of poverty alleviation plans, the health expenditures GC during the time of the fourth NDP hinted at the instability of public policies in the health care system.

Figure 3 shows the Lorenz curves for per capita adjusted health care expenditures and per capita income (total expenditures) in urban and rural areas. These curves reflect the inequalities presented in Tables 2 and 3. In Figure 3(A) and Figure 3(B) the rural Lorenz curve lies inside the urban Lorenz curve, indicating less inequality in health expenditures and income in rural areas.

Figure 4 compares Lorenz curves for health care expenditures under the first and fourth NDPs for urban and rural areas. The rural curves suggest that during the NDPs inequality was reduced, while little or no change in inequality is observed during this time period in urban areas.

Using Table 3 to understand how the KPI varies across NDPs, the most progressivity was observed in rural areas before the NDPs and during the fourth NDP, while progressivity is highest in urban areas during the first NDP. There are no statistically significant differences between the KPIs in urban and rural areas in the first, second, and third NDPs, but the KPIs are significantly higher in rural areas during the fourth NDP.

Inequality in male-headed and female-headed households As shown in Table 4 and Figure 5, for most of the last three decades inequality is slightly higher in households with female heads, and significantly higher in femaleheaded households in urban areas in terms of income. However, there is substantial variability in this relationship during this time period.

Figure 5 documented income inequality and health inequality in male-headed and female-headed households in rural and urban areas before NDP and during four NDPs. Health expenditure inequality was lowest in urban areas during the years corresponding to the third NDP, 
Table 2 Inequality measure for Per Capita real health expenditure by location; Iran: 1984-2010

\begin{tabular}{|c|c|c|c|c|c|c|}
\hline \multirow[t]{2}{*}{ Year } & \multicolumn{2}{|c|}{$\begin{array}{c}\text { Total health expenditure } \\
\text { Gini coefficient }\end{array}$} & \multicolumn{2}{|c|}{$\begin{array}{c}\text { Total health expenditure } \\
\text { Kakwani index }\end{array}$} & \multicolumn{2}{|c|}{$\begin{array}{l}\text { Total expenditure } \\
\text { Gini coefficient }\end{array}$} \\
\hline & Urban & Rural & Urban & Rural & Urban & Rural \\
\hline 1984 & 0.7510 & 0.7474 & 0.4553 & 0.4429 & 0.4875 & 0.4100 \\
\hline 1985 & 0.7409 & 0.7199 & 0.4438 & 0.4118 & 0.4789 & 0.4008 \\
\hline 1986 & 0.6940 & 0.6990 & 0.3904 & 0.3933 & 0.4667 & 0.4150 \\
\hline 1987 & 0.8031 & 0.6536 & 0.5314 & 0.3454 & 0.4635 & 0.3844 \\
\hline 1988 & 0.8074 & 0.7579 & 0.5380 & 0.4653 & 0.4525 & 0.3827 \\
\hline 1989 & 0.7518 & 0.7531 & 0.4602 & 0.4568 & 0.4372 & 0.3826 \\
\hline 1990 & 0.7310 & 0.7596 & 0.4355 & 0.4661 & 0.4148 & 0.4340 \\
\hline 1991 & 0.7597 & 0.7953 & 0.4703 & 0.5144 & 0.4467 & 0.4537 \\
\hline 1992 & 0.7856 & 0.7690 & 0.5039 & 0.4820 & 0.4195 & 0.4359 \\
\hline 1993 & 0.7326 & 0.7618 & 0.4348 & 0.4736 & 0.4076 & 0.4190 \\
\hline 1994 & 0.7634 & 0.7265 & 0.4717 & 0.4271 & 0.4239 & 0.4147 \\
\hline 1995 & 0.7528 & 0.7477 & 0.4589 & 0.4538 & 0.4171 & 0.4221 \\
\hline 1996 & 0.7569 & 0.7282 & 0.4659 & 0.4293 & 0.4332 & 0.4060 \\
\hline 1997 & 0.7429 & 0.7247 & 0.4465 & 0.4261 & 0.4308 & 0.4107 \\
\hline 1998 & 0.7453 & 0.7287 & 0.4497 & 0.4302 & 0.4276 & 0.4321 \\
\hline 1999 & 0.7088 & 0.7200 & 0.4043 & 0.4172 & 0.4271 & 0.4185 \\
\hline 2000 & 0.7134 & 0.6965 & 0.4107 & 0.3915 & 0.4241 & 0.4156 \\
\hline 2001 & 0.7153 & 0.6913 & 0.4120 & 0.3862 & 0.4309 & 0.4080 \\
\hline 2002 & 0.7121 & 0.6844 & 0.4084 & 0.3778 & 0.4361 & 0.4013 \\
\hline 2003 & 0.6684 & 0.6832 & 0.3606 & 0.3765 & 0.4257 & 0.3928 \\
\hline 2004 & 0.7706 & 0.7547 & 0.4784 & 0.4577 & 0.4202 & 0.4096 \\
\hline 2005 & 0.7664 & 0.7267 & 0.4712 & 0.4244 & 0.4273 & 0.4070 \\
\hline 2006 & 0.7673 & 0.7493 & 0.4735 & 0.4510 & 0.4422 & 0.4173 \\
\hline 2007 & 0.7851 & 0.7235 & 0.4969 & 0.4198 & 0.4403 & 0.4099 \\
\hline 2008 & 0.7693 & 0.7274 & 0.4759 & 0.4248 & 0.4129 & 0.3977 \\
\hline 2009 & 0.7451 & 0.7395 & 0.4457 & 0.4389 & 0.4010 & 0.3970 \\
\hline 2010 & 0.7452 & 0.7210 & 0.4458 & 0.4169 & 0.4016 & 0.3931 \\
\hline \multicolumn{7}{|l|}{ Total } \\
\hline & Urban & Rural & & & & \\
\hline Observations & 308,735 & 342,532 & P-Value & & & \\
\hline \multicolumn{7}{|l|}{ Gini Coeff. } \\
\hline Total health expenditure & 0.7643 & 0.7369 & 0.0364 & & & \\
\hline Total expenditure & 0.4448 & 0.4159 & 0.0001 & & & \\
\hline \multicolumn{7}{|l|}{ Kakwani index } \\
\hline Total health expenditure & 0.4699 & 0.4363 & 0.0283 & & & \\
\hline Total expenditure & 0.1692 & 0.1496 & 0.0993 & & & \\
\hline
\end{tabular}

Source: Authors' calculations from Iran's Household Expenditure and Income Survey: 1984-2010.

Notes:

1. THEXP: Total Health Expenditure; TEXP, Total Household Expenditure.

2. In the last three lines of this table we presented Gini Coefficient and KPI over the time (1984-2010).

after which inequality in male-headed households increased while it remained relatively stable among femaleheaded households.
In both urban and rural areas, income inequalities in both male-headed and female-headed households were consistently lower than health inequalities. Towards the 
Table 3 Inequality measure for Per Capita real health expenditure in Iran by location in different periods in the National Development Plans (NDPs)

\begin{tabular}{|c|c|c|c|c|c|c|}
\hline \multicolumn{7}{|c|}{ Gini Coefficient } \\
\hline \multicolumn{7}{|c|}{ Total health expenditure } \\
\hline Years & NDPs & Urban & St. Err & Rural & St. Err & P-Values \\
\hline 1984-1989 & Before NDPs & 0.7580 & $(0.017)$ & 0.7218 & $(0.016)$ & 0.1597 \\
\hline 1990-1994 & First & 0.7545 & $(0.010)$ & 0.7624 & $(0.011)$ & 0.6093 \\
\hline 995-1999 & Second & 0.7413 & $(0.009)$ & 0.7299 & $(0.005)$ & 0.2725 \\
\hline 2000-2004 & Third & 0.7160 & $(0.016)$ & 0.7020 & $(0.013)$ & 0.5268 \\
\hline 2005-2009 & Fourth & 0.7631 & $(0.006)$ & 0.7312 & $(0.004)$ & 0.0021 \\
\hline \multicolumn{7}{|c|}{ Total expenditure } \\
\hline 984-1989 & Before NDPs & 0.4521 & $(0.007)$ & 0.3868 & $(0.007)$ & 0.0001 \\
\hline 1990-1994 & First & 0.4150 & $(0.006)$ & 0.4130 & $(0.006)$ & 0.8282 \\
\hline 995-1999 & Second & 0.4169 & $(0.002)$ & 0.4029 & $(0.005)$ & 0.0352 \\
\hline $2000-2004$ & Third & 0.4199 & $(0.002)$ & 0.3941 & $(0.004)$ & 0.0003 \\
\hline 2005-2009 & Fourth & 0.4168 & $(0.008)$ & 0.3948 & $(0.004)$ & 0.0292 \\
\hline \multicolumn{7}{|c|}{ Kakwani index } \\
\hline \multicolumn{7}{|c|}{ Total health expenditure } \\
\hline 1984-1989 & Before NDPs & 0.4193 & $(0.019)$ & 0.4699 & $(0.023)$ & 0.1164 \\
\hline 1990-1994 & First & 0.4726 & $(0.014)$ & 0.4632 & $(0.013)$ & 0.6360 \\
\hline 1995-1999 & Second & 0.4313 & $(0.006)$ & 0.4451 & $(0.011)$ & 0.2980 \\
\hline 2000-2004 & Third & 0.3979 & $(0.015)$ & 0.4140 & $(0.019)$ & 0.5242 \\
\hline 2005-2009 & Fourth & 0.4293 & $(0.005)$ & 0.4682 & $(0.008)$ & 0.0024 \\
\hline \multicolumn{7}{|c|}{ Total expenditure } \\
\hline 1984-1989 & Before NDPs & 0.1835 & $(0.005)$ & 0.1374 & $(0.004)$ & 0.0000 \\
\hline 1990-1994 & First & 0.1542 & $(0.005)$ & 0.1602 & $(0.005)$ & 0.4031 \\
\hline 1995-1999 & Second & 0.1572 & $(0.002)$ & 0.1508 & $(0.003)$ & 0.1058 \\
\hline 2000-2004 & Third & 0.1573 & $(0.002)$ & 0.1427 & $(0.003)$ & 0.0021 \\
\hline 2005-2009 & Fourth & 0.1529 & $(0.005)$ & 0.1415 & $(0.002)$ & 0.0686 \\
\hline
\end{tabular}

Source: Authors' calculations from Iran's Household Expenditure and Income. Survey: 1984-2010.

end of the analysis period, during the time corresponding with the third and fourth NDPs, the urban inequality gap closed in male- and female-headed households in terms of income. The same movement did not occur in rural areas, where inequality was persistently greater among female-headed households.

\section{Discussion}

This paper provides a descriptive account of inequality in health care expenditures in Iran from 1984 to 2010; our findings are similar to other findings in different periods and policy areas. For example, Isfahani used HIES data from 1984 to 2005 and calculated the GC for total expenditures and concluded that, in spite of the implementation of different governmental policies, inequality and poverty remained significant problems in Iran [19]. Mahmodi used HIES data from 1989 to 1994 and used consumption as a proxy for income and concluded that not only was inequality in Iran very high ${ }^{\mathrm{a}}$, but the gap between urban and rural areas was especially wide [31].

Our focus on health expenditures identified even greater inequality in this category than is evident in the economy as a whole. Iran has introduced several reforms to address inequalities in the health care system during this time period [16]. Perhaps the most important intervention was the introduction of health insurance as part of the second NDP in 1995 (which sought to decrease the financial burden of health care). The universal health insurance coverage law was ratified to extend coverage to everyone, giving priority to the poor, needy, and rural groups $^{\mathrm{b}}$. It is possible that the implementation of this law contributed to the decline in inequality observed during the third NDP.

In 2004, at the start of the fourth NDP, the Ministry of Welfare and Social Security (MWSS) was established to develop and improve the health insurance schemes. However, the trend of GC for health care expenditures suggests that the fourth NDP and MWSS were not able to achieve the objective of decreasing inequalities in the health system in Iran. While there could be a lag between the implementation of the policies and the impact they have on inequalities, the GC for health care expenditures remains higher than third -NDP levels through 2010.

While there were some improvements in inequality due to the NDPs, these appear to have been mostly temporary, and inequality in health expenditures surged during the latter half of the 2000s. This suggests that the strategies adopted as part of the NDPs were not able to sustainably reduce inequality in health care expenditures.

Our findings show that in spite of several major initiatives, such as the development of PHC networks and medical facilities in rural areas (in the first and second NDPs) and introduction of universal health insurance coverage in 1995 (in the second NDP), inequality has not declined. This is consistent with results from a study by Ibrahimipour et al., that noted that the lack of government participation was one of the main reasons for the failure to reach universal coverage of health insurance [16].

The distribution of catastrophic payments reflects the fairness in financing of health systems [41]. To understand the impact of NDPs on households, we considered the World Health Organization's (WHO) measure for catastrophic payments (total health expenditure over total expenditure greater than or equal to 40\%) [42]. According to this threshold, during the selected years on average $6.97 \%$ of the households in this study faced catastrophic levels of health care expenditures. The highest percentage of households met this threshold during the fourth NDP, including $15.12 \%$ of rural households and $16.63 \%$ of urban households. These rates peaked for urban and rural areas in the last two study years (2009 and 2010). 

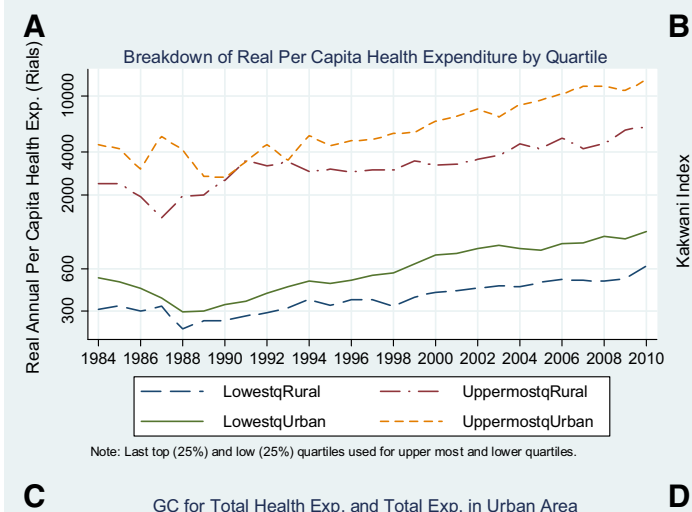

B
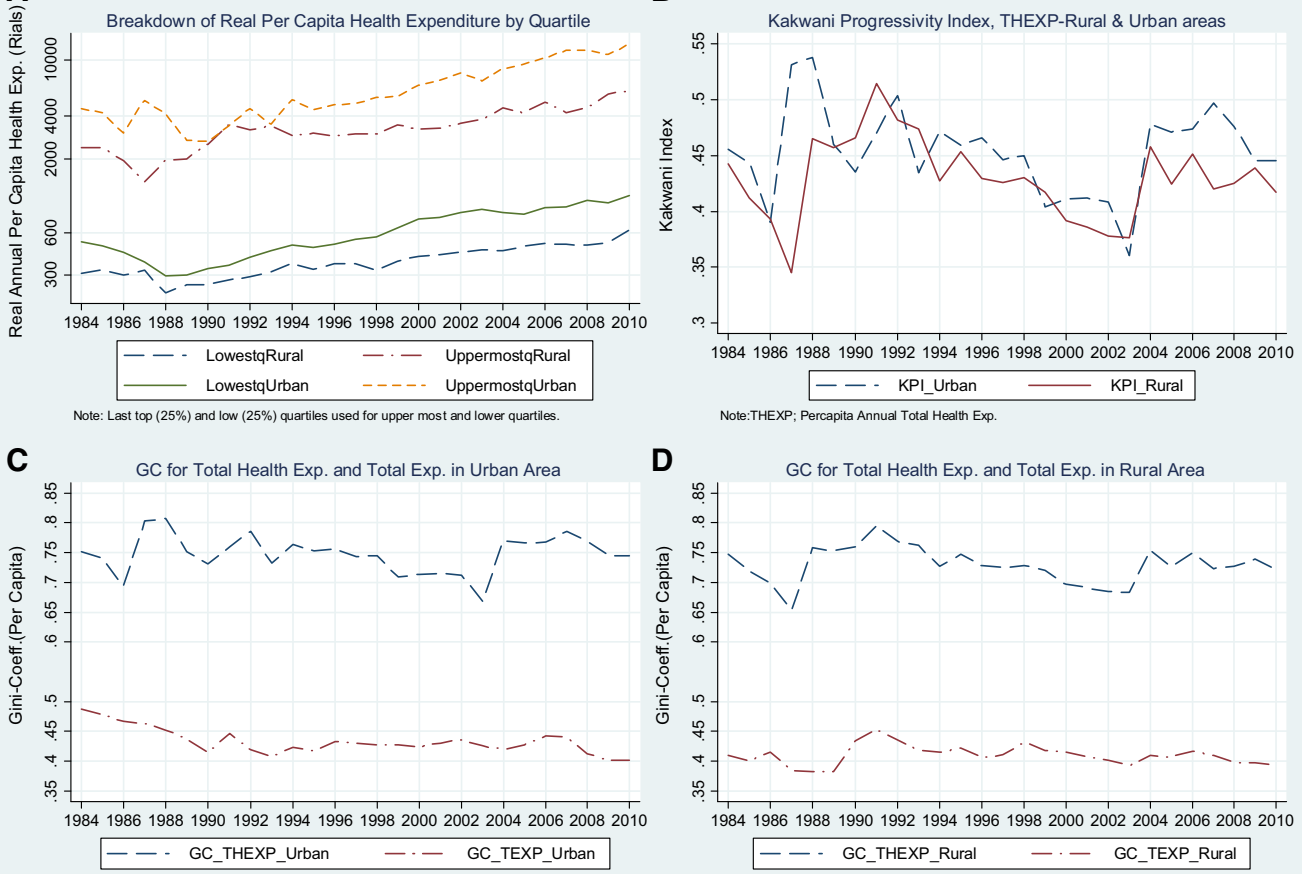

D

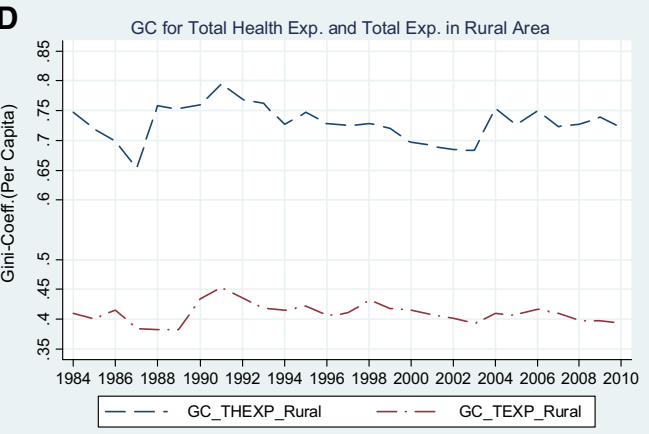

Figure 2 Comparing changes in inequalities in total health exp.; Iran-1984-2010.
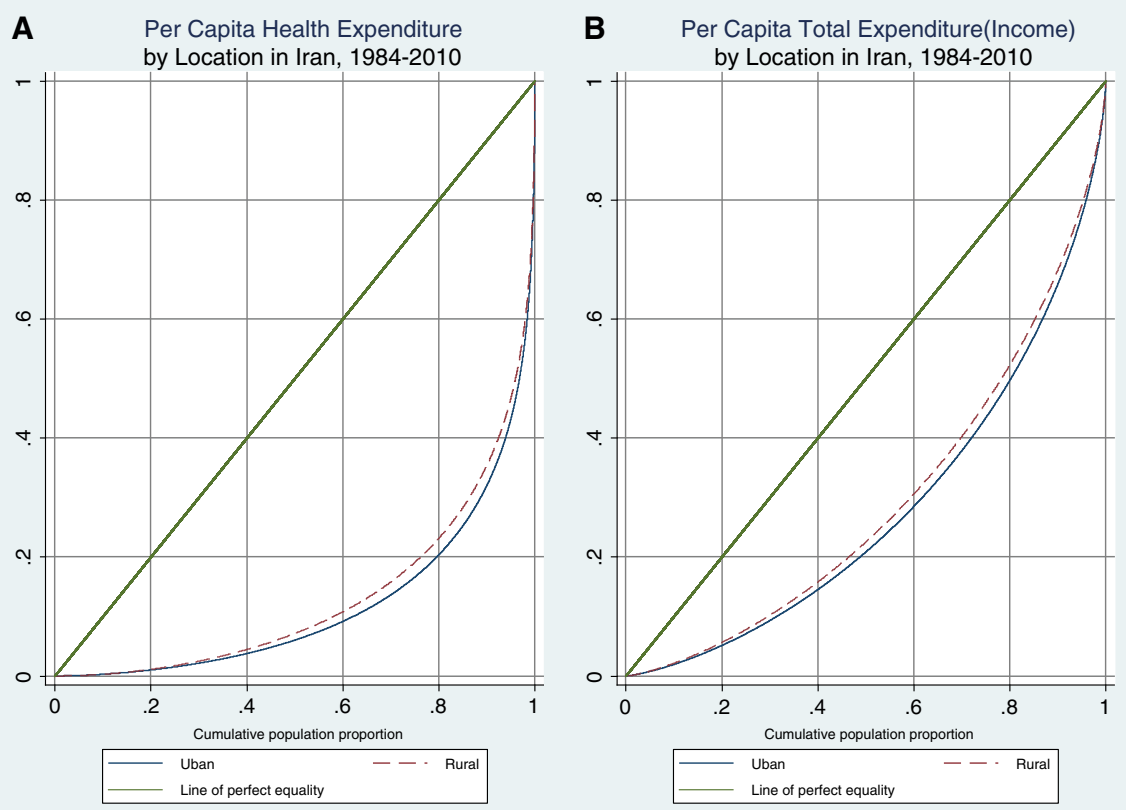

Figure 3 Generalized Lorenz Curve for Per Capita Health Exp. and Total Exp. by Location in Iran, 1984-2010. 

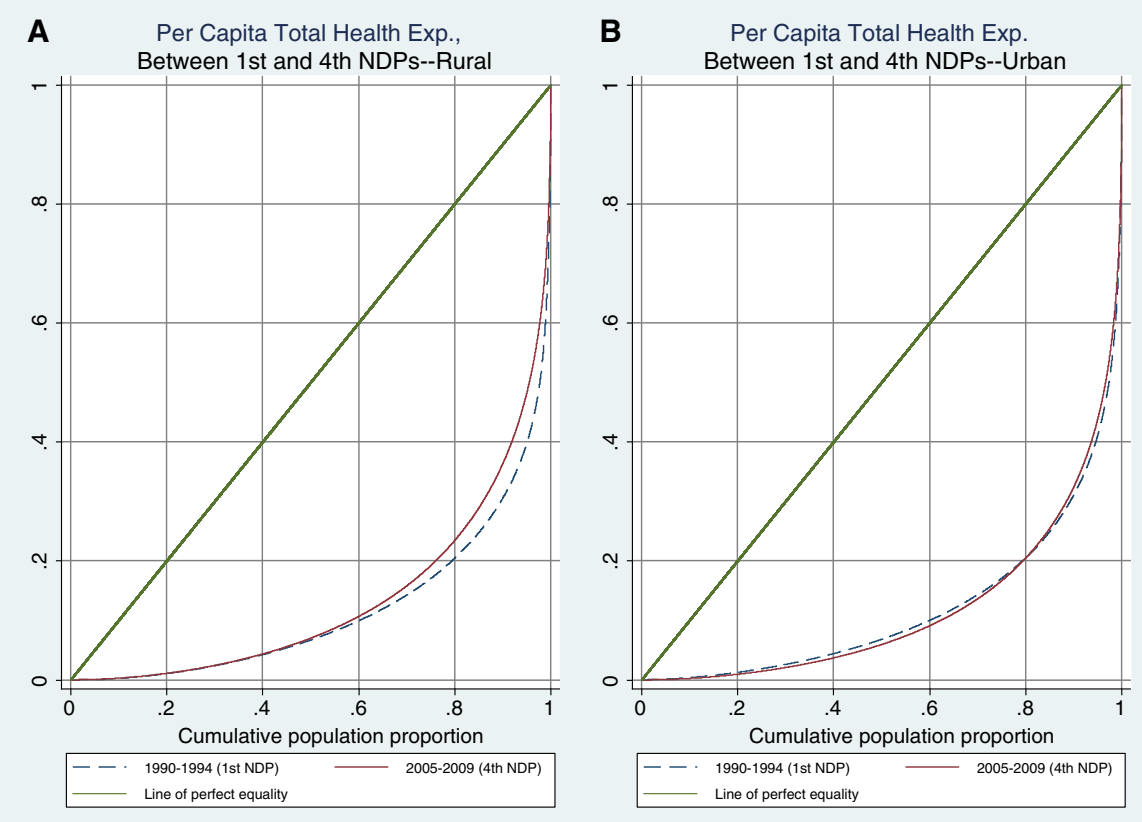

Figure 4 Comparing Generalized Lorenz Curve for Per Capita Health Exp. Between 1st and 4th NDPs in Iran.

Our findings are similar to those presented in the 2007 World Bank Annual Report, which described funding for health in Iran as highly progressive with large out-of-pocket payments [43]. A study by Kavosi, which analyzed catastrophic payments in Iran from 2003 to 2008 also concluded that policy interventions did not decrease people's contribution to health care expenditures during this period [10]. Furthermore, a study by Daneshkohan in Kermanshah reported that 22\% of households in this region faced catastrophic levels of health expenditures in 2008 [44].

\section{Strengths and limitations}

Access to reliable information in upper middle income countries such as Iran is one of the most significant obstacles to conducting this type of research. Despite the lack of official statistics in Iran, the data on household expenditures provide a reliable source of information for decision-making. The stability and reliability of self-reported household expenditure surveys are the main strength of these data [45]. However there are some well known issues with using household expenditure data such as inaccurate self-reporting and skewing of the data

Table 4 Inequality measure for per capita real health expenditures and total expenditure in male-headed and female-headed in urban and rural areas; Iran: 1984-2010

\begin{tabular}{|c|c|c|c|c|c|c|}
\hline \multirow{2}{*}{$\begin{array}{l}\text { Location/Inequality } \\
\text { Measures }\end{array}$} & \multicolumn{3}{|c|}{ Urban } & \multicolumn{3}{|c|}{ Rural } \\
\hline & Male-headed & Female-headed & & Male-headed & Female-headed & \\
\hline \multirow[t]{2}{*}{ Observations } & 280,570 & 28,165 & & 303,895 & 38,636 & \\
\hline & $90.88 \%$ & $9.12 \%$ & & $88.72 \%$ & $11.28 \%$ & \\
\hline Gini coefficient & & & p-value & & & p-value \\
\hline Total health expenditure & 0.7631 & 0.7681 & 0.3334 & 0.7352 & 0.7474 & 0.9696 \\
\hline Total Expenditure & 0.44037 & 0.4826 & 0.0160 & 0.4122 & 0.4420 & 0.0573 \\
\hline \multicolumn{7}{|l|}{ Kakwani index } \\
\hline Total health expenditure & 0.4687 & 0.4732 & 0.7678 & 0.4346 & 0.4472 & 0.0551 \\
\hline Total expenditure & 0.1661 & 0.1965 & 0.0183 & 0.1471 & 0.1678 & 0.9035 \\
\hline
\end{tabular}

Source: Authors' calculations from Iran's Household Expenditure and Income Survey: 1984-2010.

Notes:

1. Per Capita Total Health Expenditure and Total Expenditure were adjusted by considering CPI $(1997=100)$.

2. GC and KPI reported inequalities in pool data between 1984-2010. 


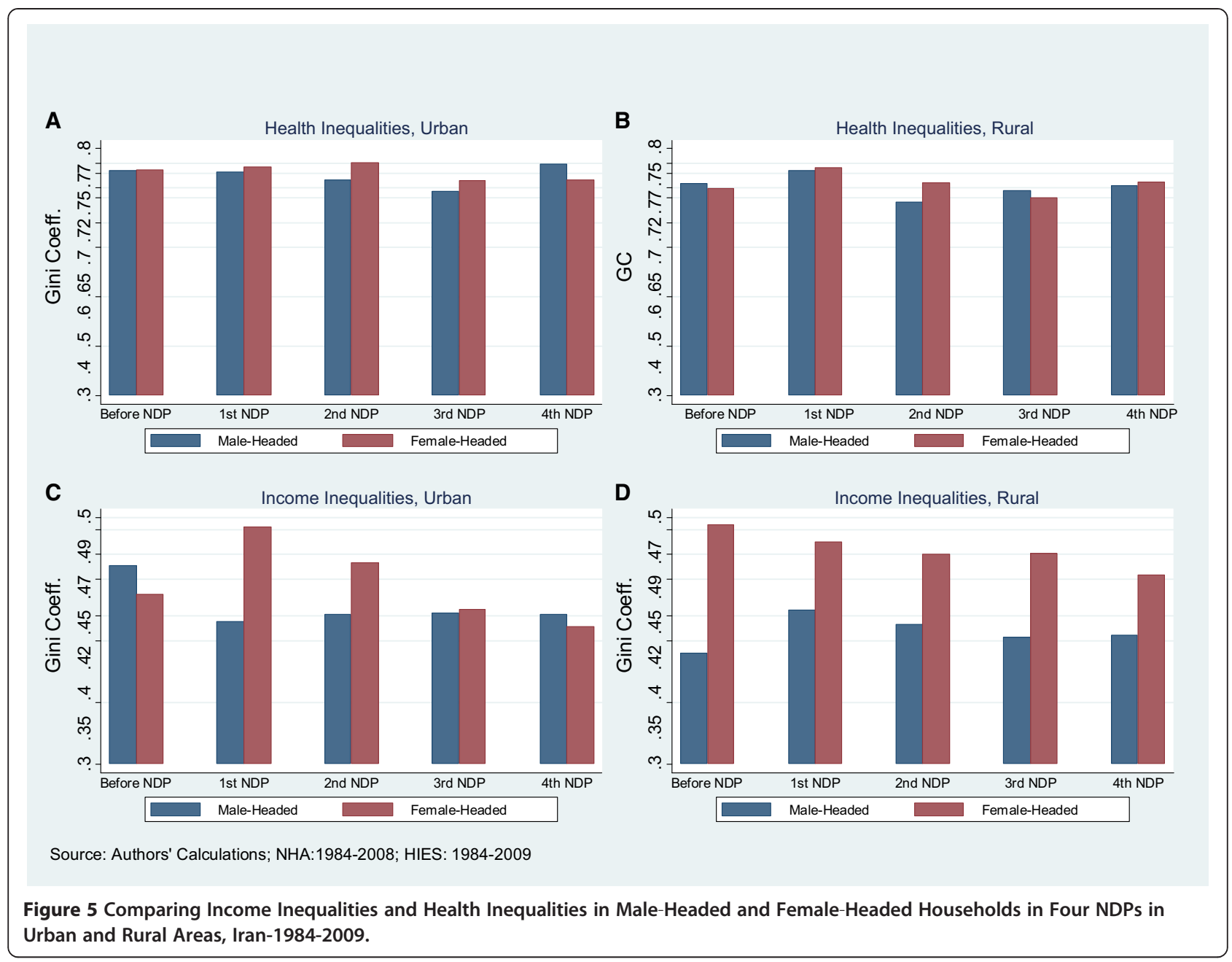

when wealthier households hire workers and supply them with food [46,47]. In spite of these drawbacks, consumption is considered to be a reliable indicator of household income in both developing and developed countries [45].

It is worth noting that this study does not attempt to identify the reasons why the NDPs succeeded or failed to reduce inequalities in health care expenditures. It only investigates the effects of the implemented policies on the inequality in health care expenditures of households. This is the first comprehensive study which assesses all of Iran's developmental plans after the revolution and compares the objectives of the plans with the distribution of health expenditures among Iranian households.

\section{Conclusions}

Over the past three decades Iran implemented four NDPs which introduced several reforms in the health care system. To understand the impact of NDPs on health expenditures of households we considered indicators of inequality (Gini coefficient) and out-of-pocket progressivity (Kakwani index).
Comparing the trend of out-of-pocket payments in Iran showed that it consistently represented more than half of total health care expenditures, with no significant change during the course of the NDPs. A comparison of inequality in health care expenditures over time showed that inequality was persistent, and was higher in urban areas.

Considering these effects, policymakers need to consider revising existing policies to improve equality in Iran. It seems that a revision of social protection, social safety nets, and health insurance schemes would be options for decreasing inequalities in health care expenditures in this area. Other mechanisms, such as ensuring better coverage for individuals with certain chronic diseases, the elderly, and other vulnerable groups may also improve the current situation.

The results from this paper may be relevant to other countries with similar health care systems, and those countries where oil is the main source of government revenue such as Algeria and Venezuela, as well as other countries in the region such as Turkey and Saudi Arabia which have similar socio-demographic profiles. 


\section{Endnotes}

${ }^{a}$ Despite an increase in Iran's revenue from 1990 to 1992-due to the sudden oil price hike-the inequality gap persisted in rural areas in late 1994. The increase in 1998 can be attributed to the economic shock in the country due to the impact of the economic reform in Iran.

${ }^{\mathrm{b}}$ Before the MSIO was established civil servants were the only ones covered by public health insurance.

\section{Abbreviations}

CBI: Central Bank of Iran; CPI: Consumer Price Index; GC: Gini Coefficient; GDP: Gross Domestic Product; HIES: Household Income and Expenditure Survey; KPI: Kakwani progressivity index; MSIO: Medical Services Insurance Organization; MOHME: Ministry of Health and Medical Education; NDPs: National Development Plans; NGOs: Non-governmental organizations; PHC: Primary health care; SSO: Social Security Organization; SCI: Statistical Center of Iran; MWSS: The Ministry of Welfare and Social Security.

\section{Competing interests}

The authors' declare that they have no competing interests.

\section{Authors' contributions}

$\mathrm{HZ}$ participated in the design and concept of the study, carried out the statistical analysis, and drafted the manuscript. AT participated in the design, concept of the study and drafting of the manuscript. JD, GG and MG participated in the interpretation of the results and revision of the manuscript. All authors read and approved the final manuscript.

\section{Acknowledgements}

This research paper was conducted at the Health Policy and Management and International Health Departments, Johns Hopkins Bloomberg School of Public Health. There are no sponsors or conflicts of interests.

The authors would like to thank Steel R. Stewart for his comments and Martin Blair for his valuable editorial comments. Special thanks to Professor Ky Xu for his very useful comments on various parts of the research and the article.

\section{Author details}

'Health Policy and Management Department, Johns Hopkins Bloomberg School of Public Health, 624 North Broadway, Baltimore, Maryland 21205, USA. ${ }^{2}$ Department of International Health, Johns Hopkins Bloomberg School of Public Health, 615 North Wolfe Street, Baltimore, Maryland 21205, USA. ${ }^{3}$ Hospital Management Research Center, Iran University of Medical Sciences, Tehran, Iran. ${ }^{4}$ Graduate School of Public Health, University of Pittsburgh, 130 DeSoto Street A614 Crabtree, Pittsburgh, PA 15261, USA. ${ }^{5}$ Department of Economics, University of Siena, Piazza San Francesco, 7, Siena, Italy. ${ }^{6}$ Centre for Health Research, School of Medicine, University of Western Sydney, Sydney, New South Wales, Australia. ${ }^{7}$ Faculty of Health Sciences, University of Sydney, Sydney, New South Wales, Australia.

Received: 11 October 2013 Accepted: 6 May 2014

Published: 27 May 2014

\section{References}

1. Commission on Social Determinants of Health: Closing the gap in a generation: health equity through action on the social determinants of health. Final Report of the Commission on Social Determinants of Health. Geneva: World Health Organization; 2008.

2. Zare $\mathrm{H}$, Gerard $\mathrm{A}$ : Trends in cost sharing among selected high income countries-2000-2010. Health Policy 2013, 112:35-44.

3. Xu K, Evans DB, Carrin G, Aguilar-Rivera AM, Musgrove P, Evans T: Protecting households from catastrophic health spending. Health Aff 2007, 26:972-983.

4. Nuru-Jeter AM, LaVeist TA: Racial segregation, income inequality, and mortality in US metropolitan areas. J Urban Health 2011, 88:270-282.

5. Palmer N, Mueller DH, Gilson L, Mills A, Haines A: Health financing to promote access in low income settings-how much do we know? Lancet 2004, 364:1365-1370.
6. Su TT, Kouyaté B, Flessa S: Catastrophic household expenditure for health care in a low-income society: a study from Nouna District, Burkina Faso. Bull World Health Organ 2006, 84:21-27.

7. Van Doorslaer E, O'Donnell O, Rannan-Eliya RP, Somanathan A, Adhikari SR, Garg CC, Harbianto D, Herrin AN, Huq MN, Ibragimova S, Karan A, Lee TJ, Leung GM, Rachel Lu JF, Wan NC, Badri Raj Pande BR, Racelis R, Tao S, Tin K, Tisayaticom K, Trisnantoro L, Vasavid C, Zhao Y: Catastrophic payments for health care in Asia. Health Econ 2007, 16:1159-1184.

8. Organization WH: Paying for health services, fact sheet, No 320, Social health protection. In http://www.who.int/mediacentre/factsheets/fs320.pdf.

9. Nguyen HT, Rajkotia Y, Wang H: The financial protection effect of Ghana National Health Insurance Scheme: evidence from a study in two rural districts. Int J Equity Health 2011, 10:4.

10. Kavosi Z, Rashidian A, Pourreza A, Majdzadeh R, Pourmalek F, Hosseinpoor AR, Mohammad K, Arab M: Inequality in household catastrophic health care expenditure in a low-income society of Iran. Health Policy Plan 2012, 27:613-623.

11. Ilias S: Iran's Economic Conditions: US Policy Issues. Washington DC: Congressional Research Service, The Library of the Congress; 2009:40.

12. Amuzegar J: Iran's 20-year economic perspective: promises and pitfalls. Middle East Policy 2009, 16:41-57.

13. Van der Ploeg F: Natural resources: curse or blessing? J Econ Lit 2011, 49:366-420

14. Kazemian M: National health accounts in Iran. Soc Secur Q 1997, 1:1-17.

15. Khiabani N, Mazyaki A: Are public policies effective in alleviating family income inequality in Iran? Volume 2011. Munich Personal RePEc Archive; 2009. http://mpra.ub.uni-muenchen.de/id/eprint/18278.

16. Ibrahimipour H, Maleki MR, Brown R, Gohari M, Karimi I, Dehnavieh R: A qualitative study of the difficulties in reaching sustainable universal health insurance coverage in Iran. Health Policy Plan 2011, 26:485-495.

17. Statistical Center of Iran: Iran's National Health Account-2003-2008. Terhran, Iran: Statistical Center of Iran; 2011:1-158.

18. Iranian Parliament (Majles-e Shoraye Eslami): First Social, Economical and Cultural National Development Plan-Iran. Tehran: Iranian Parliament (Majles) Research Center, Iranian Parliament (Majles-e Shoraye Eslami); 1990. http://rc.majlis.ir/fa/law/show/91755.

19. Salehi-Isfahani D: Poverty, inequality, and populist politics in Iran. J Econ Inequal 2009, 7:5-28.

20. Iranian Parliament (Majles-e Shoraye Eslami): Universal Health Insurance Coverage. Tehran: Medical Service Insurance Organization; 1994.

21. Iranian Parliament (Majles-e Shoraye Eslami): Third Social, Economical and Cultural National Development Plan-Iran. Tehran: Iranian Parliament (Majles) Research Center, Iranian Parliament (Majles-e Shoraye Eslami); 2000. http://rc.majlis.ir/fa/law/show/93301.

22. Safikhani H, Zare H: Health insurance development in I.R. Iran and poverty alleviation. Tehran, Iran: Medical Service Insurance Organization; 2003.

23. Iranian Parliament (Majles-e Shoraye Eslami): Second Social, Economical and Cultural National Development Plan-Iran. Tehran: Iranian Parliament (Majles) Research Center, Iranian Parliament (Majles-e Shoraye Eslami); 1994. http:// rc.majlis.ir/fa/law/show/92488.

24. Iranian Parliament (Majles-e Shoraye Eslami): Fourth Social, Economical and Cultural National Development Plan-Iran. Tehran: Iranian Parliament (Majles) Research Center, Iranian Parliament (Majles-e Shoraye Eslami); 2004.

25. Statistical Center of Iran: Iran's Population. 2014. http://www.amar.org.ir/ Default.aspx?tabid $=103$.

26. Zare H: Health care systems around the world, Volume II. Tehran, Iran: Medical Service Insurance Organization; 2006.

27. Hajizadeh M: Equity of Health Care: Empirical Studies in Iran and Australia, PhD thesis. The University of Queensland School of Economics; 2010.

28. Statistical Center of Iran: Records Complex-Household Expenditure and Income Survey in Urban and Rural Area. pp. 800. Tehran: Statistical Center of Iran; 2005:800.

29. Statistical Center of Iran: Household, Expenditure and Income. 2014. http:// www.amar.org.ir/Default.aspx?tabid=1507.

30. Statistical Center of Iran, Office of International Affairs and Public Relations: Household Expenditure and Income Survey. 2003. http:/laborsta.ilo.org/ applv8/data/SSM6/E/325A.html: Access 17 March 2014.

31. Mahmoudi V: Growth-equity decomposition of a change in poverty: an application to Iran. In UNU/WIDER development conference on growth and poverty. Helsinki: 2001. 
32. Mahmoudi V: Consumption distribution in Iran: a statistical overview. Iran Econ Rev 2005, 10:85-102.

33. Haughton JH, Khandker SR: Handbook on poverty and inequality. Washington, DC: World Bank; 2009.

34. Deaton A: The analysis of household surveys a microeconometric approach to development policy. Baltimore: Published for the World Bank [by] Johns Hopkins University Press; 1997.

35. Central Bank of Islamic Republic of Iran: Consumer Price Index (Time Series; 1984-2010). Tehran: Central Bank of Islamic Republic of Iran; 2014. http://www.cbi.ir/default_en.aspx.

36. Statistical Center of Iran: Consumer Price Index (Time Series; 1984-2010). Statistical Center of Iran; 2014. http://www.amar.org.ir 1984-2010.

37. De Maio FG: Income inequality measures. J Epidemiol Community Health 2007, 61:849-852.

38. Wagstaff A: Inequality aversion, health inequalities and health achievement. J Health Econ 2002, 21:627-641.

39. Wagstaff A, Van Doorslaer E: Equity in health care finance and delivery. Handb Health Econ 2000, 1:1803-1862.

40. Murray CJ, Knaul F, Musgrove P, Xu K, Kawabata K: Defining and measuring fairness in financial contribution to the health system (Issue 24 of GPE discussion paper). World Health Organization; 2001. http://www.who.int/ healthinfo/paper24.pdf.

41. Organization WH: The world health report 2000: health systems: improving performance. Switzerland: World Health Organization; 2000.

42. Xu K, Evans DB, Kawabata K, Zeramdini R, Klavus J, Murray CJ: Household catastrophic health expenditure: a multicountry analysis. Lancet 2003, 362:111-117.

43. World Bank: 2007 World development indicator (WD107 section2.indd) Distribution of income or consumption. Washington, DC: World Bank; 2007. http://siteresources.worldbank.org/DATASTATISTICS/Resources/table2_7.pdf.

44. Daneshkohan A, Karami M, Najafi F, Matin BK: Household catastrophic health expenditure. Iran J Public Health 2011, 40:94-99.

45. Deaton A: Policy implications of the gradient of health and wealth Health Aff 2002, 21:13-30.

46. Deaton A: The analysis of household surveys: a microeconometric approach to development policy. Baltimore: Johns Hopkins University Press, World Bank Publications; 1997

47. Zare H, Trujillo AJ, Leidman E, Buttorff C: Income elasticity of health expenditures in Iran. Health Policy Plan 2013, 28:665-679.

doi:10.1186/1475-9276-13-42

Cite this article as: Zare et al:: Health inequalities and development plans in Iran; an analysis of the past three decades (1984-2010). International Journal for Equity in Health 2014 13:42.

\section{Submit your next manuscript to BioMed Central and take full advantage of:}

- Convenient online submission

- Thorough peer review

- No space constraints or color figure charges

- Immediate publication on acceptance

- Inclusion in PubMed, CAS, Scopus and Google Scholar

- Research which is freely available for redistribution 